\title{
CLINICO-PATHOLOGICAL STUDY: 48 CASES OF CARCINOMA BREAST AT TERTIARY CARE CENTRE IN RURAL AREA
}

\author{
Pravin Wamanrao Nikhade1, Ajay Dnyanoba Subhedar², Shakuntala Limbaji Shelke3, Avinash Shivaji Pawara ${ }^{4}$
}

${ }^{1}$ Assistant Professor, Department of Surgery, Government Medical College, Dhule, Maharashtra. ${ }^{2}$ Associate Professor, Department of Surgery, Government Medical College, Dhule, Maharashtra. ${ }_{3}^{3}$ Associate Professor, Department of Radiology, Government Medical College, Dhule, Maharashtra. ${ }_{4}^{4}$ Assistant Professor, Department of Surgery, Government Medical College, Dhule, Maharashtra.

\begin{abstract}
BACKGROUND

Carcinoma breast is the most common site of specific cancer in women. In India, the incidence of breast cancer is increasing rapidly to be number one cancer, now cervical cancer became second in place. Breast lump is the commonest symptom and once clinically apparent carcinoma tends to spread distantly which greatly varies from patient to patient and is characteristic of heterogeneity of the disease.

The aim of the study is to study carcinoma breast with respect to various risk factors, age distribution, clinical presentation and histopathological findings.
\end{abstract}

\section{MATERIALS AND METHODS}

This is a hospital-based prospective observational study and data used was obtained from 48 cases that were evaluated at our institute from September 2013 to August 2015 and diagnosed to have carcinoma breast.

\section{RESULTS}

All the patients were females with average age of 51 years. Average age of menarche was 13 years. with almost equal proportions of pre- and post-menopausal women. Only one patient was nulliparous, rest of all the patients breast fed their children; $8.3 \%$ of the patients had a family history of disease and they all had earlier age of presentation. Duration of symptoms was more than 6 months in $43.8 \%$ cases, which reflects negligence of patients. Lump in breast was a presenting complaint in all the patients (100\%) followed by nipple retraction (33.3\%); $14.6 \%$ of patients had stage I disease, $39.6 \%$ had stage II disease and $45.8 \%$ had stage III disease; $81.3 \%$ of cases were of infiltrating ductal carcinoma; $60.4 \%$ of patient's samples were ER positive, while $52.1 \%$ were PR positive; $83.2 \%$ of cases were discharged without any complications.

\section{CONCLUSION}

FNAC was highly effective in diagnosing malignancy. Infiltrating ductal carcinoma was the most common histopathological type. A significant proportion of patients were hormone receptor positive depicting the role of hormonal therapy in the management. Early breast carcinomas are well treated with modified radical mastectomy with a need of chemoradiation in selected cases. The management of Locally Advanced Breast Carcinoma requires complex multidisciplinary approach. Raising awareness about the screening procedures and treatment of breast cancer can help reducing mortality.

\section{KEYWORDS}

Adjuvant Chemotherapy, Breast Cancer, Menarche, Metastatic, Modified Radical Mastectomy, Radiotherapy, Risk Factors, Tumour Markers.

HOW TO CITE THIS ARTICLE: Nikhade PW, Subhedar AD, Shelke SL, et al. Clinico-pathological study: 48 cases of carcinoma breast at tertiary care centre in rural area. J. Evolution Med. Dent. Sci. 2016;5(101):7429-7434, DOI: 10.14260/jemds/2016/1682

\section{BACKGROUND}

Carcinoma breast accounts for $26 \%$ of all newly diagnosed cancers in females and are responsible for $15 \%$ of the cancer related death in women. ${ }^{1}$ It is seen rarely before the age of 30. Thereafter, its incidence rises rapidly. In developing countries, it accounts for $1 \%-3 \%$ deaths. $^{2}$ It causes 5,19,000 deaths in a year worldwide; about 9,00,000 women are diagnosed per year. Incidence of breast cancer is $0.26 / 1,00,000$ in males and

Financial or Other, Competing Interest: None.

Submission 14-11-2016, Peer Review 08-12-2016,

Acceptance 14-12-2016, Published 19-12-2016.

Corresponding Author:

Dr. Ajay Dnyanoba Subhedar

Plot No. 78,

Parijat Near Navjeevan Blood Bank,

Vaibhav Nagar, Dhule, Maharashtra.

E-mail: subhedarajar74@gmail.com

DOI: $10.14260 /$ jemds/2016/1682
$20.01 / 1,00,00$ in females. While mortality associated with breast cancer is $1.20 / 1,00,000$ in males and $4.32 / 1,00,000$ in females. Deaths from breast cancer have increased during the past 60 years in every country. ${ }^{3}$

In India an increasing trend in incidence is reported. As per various studies, 1 in 22 females are likely to have breast cancer in their lifetime. The rise is mainly documented in metros and urban India. ${ }^{4}$ To generate the reliable data on magnitude and pattern of cancer, India started National Cancer Registry Program in 1981.5 Upto 2003 the program comprised of six population based cancer registry and one registry serving rural area covering the total population of 35.7 million (only $3.5 \%$ of the Indian total population $)^{6}$ and an increasing trend in incidence is reported from various registries of national cancer registry project and now India is a country with largest estimated number of breast cancer deaths worldwide. ${ }^{7,8}$ In India it is difficult for early diagnosis of carcinoma breast in lower strata females, mainly because of lack of breast cancer 
screening program, scarcity of diagnostic tools and ignorance towards health of female. Vital multidisciplinary approach of treatment of carcinoma breast is available over a very few centres. Marriage at an early age, early and multiple childbirths and breastfeeding of all children for a long period of time is the norm in most Indian socities. ${ }^{9}$ Almost all Indian breast cancer patients detect their disease by themselves at a stage when it presents with palpable lump. The management of breast cancer requires a multidisciplinary approach involving surgeon, medical oncologist, pathologists and radiotherapists as well as other medical professionals. ${ }^{10}$ It is most often observed that due to lack of knowledge and ignorance, patients of carcinoma breast clinically present in a later stages of disease. And because of this, in India most patients presents to the healthcare facilities at the stage of Locally Advanced Breast Carcinoma. Treatment of this advanced carcinoma mainly requires multidisciplinary approach.

\section{MATERIALS AND METHODS}

Diagnosed cases of carcinoma breast from September 2013 to August 2015 were included in this hospital-based prospective observational study.

\section{Inclusion Criteria}

- All proven cases of carcinoma breast.

- Patients who belonged to clinical Stage I, Stage II and Stage III disease.

\section{Exclusion Criteria}

- Male breast carcinoma.

- $\quad$ Stage IV patients.

- Patients with benign breast disease.

\section{RESULTS}

Out of 48 cases studied, $14.6 \%$ were less than 40 years of age and maximum were within 41 to 50 years' age group (43.7\%). Within 51 to 60 and 61 to 70 years of age groups 9 (18.8\%) and $7(14.6 \%)$ women were present respectively. Only 4 women $(8.3 \%)$ were above 70 years age.

Family history of breast carcinoma was noted in 4 cases (8.3\%). In this study, 21 women (43.8\%) with symptoms related to breast carcinoma were present after 6 months of initiation of symptoms, while 16 women (33.3\%) were having symptoms within 3 months to 6 months' duration. And 11 women $(22.9 \%)$ had the symptoms for duration of less than 3 months. All 48 women (100\%) having breast carcinoma had presented with lump, while 7 (14.6\%) had complained of pain in breast. Ulceration over breast and other skin changes were seen in 9 patients (18.8\%), 16 females had nipple retraction (33.3\%), 5 had nipple discharge $(10.4 \%)$ and 4 were presented with axillary mass $(8.3 \%)$.

\begin{tabular}{|c|c|}
\hline Characteristics & Subjects and \% \\
\hline Age Groups in Years & \\
\hline $20-30$ & $2(4.17 \%)$ \\
\hline $30-40$ & $5(10.42 \%)$ \\
\hline $40-50$ & $21(43.7 \%)$ \\
\hline $50-60$ & $9(18.8 \%)$ \\
\hline $60-70$ & $7(14.6 \%)$ \\
\hline Above 70 & $4(8.3 \%)$ \\
\hline
\end{tabular}

\begin{tabular}{|c|c|}
\hline Mean \pm SD : $51 \pm 12$ & \\
\hline Family History & $4(8.3 \%)$ \\
\hline Present & $44((91.7 \%)$ \\
\hline Absent & $11(22.9 \%)$ \\
\hline Duration of Symptoms & $16(33.3 \%)$ \\
\hline Less than 3 months & $21(43.8 \%)$ \\
\hline 3 to 6 months & $48(100 \%)$ \\
\hline More than 6 months & $16(33.3 \%)$ \\
\hline Clinical Presentation & $9(18.8 \%)$ \\
\hline Lump in breast & $7(14.6 \%)$ \\
\hline Nipple retraction & $5(10.4 \%)$ \\
\hline Ulcer/other skin changes & $4(8.3 \%)$ \\
\hline Pain/discomfort & Nipple discharge \\
\hline \multicolumn{2}{|c|}{ Axillary mass } \\
\hline \multicolumn{2}{|c|}{ Table 1. Distribution of Study Subjects } \\
According to Clinical Factors (n = 48)
\end{tabular}

In our study, all the 48 included patients were females. In $50 \%$ of these females the age of attainment of menarche was between 13 and 15 years, while 17 females (35.4\%) reported less than 13 years as age of menarche (Mean \pm SD : $13 \pm 1.7$ ); 23 females $(47.9 \%)$ were premenopausal, while 25 females (52.1\%) were post-menopausal at the time of detection of breast carcinoma. We noted $64.6 \%$ of patients had a reproductive period of more than 30 years. Mean \pm SD : $31 \pm$ 4.3; 17 females (35.4\%) had given first birth when they were less than 20 years of age; 22 females (45.8\%) delivered first time between 21 - 25 years of age (Mean \pm SD: $21 \pm 4$ ); 47 females $(97.9 \%)$ had breast fed their children, only 1 patient $(2.1 \%)$ was nulliparous. In the study only 1 female was nulliparous, parity 1 was the most common in $35.5 \%$ of the patients, parity 2 in 25\% females and parity 4 in $23 \%$ females (Mean \pm SD : $3.3 \pm 1.2$ ).

\begin{tabular}{|c|c|}
\hline Age at Menarche $(n=48)$ & \\
\hline Less than 13 & $17(35.4 \%)$ \\
\hline $13-15$ & $24(50 \%)$ \\
\hline More than 15 & $7(14.6 \%)$ \\
\hline \multicolumn{2}{|l|}{ Mean \pm SD : $13 \pm 1.7$} \\
\hline \multicolumn{2}{|l|}{ Age at First Delivery $(n=47)$} \\
\hline Less than 20 & $17(35.4 \%)$ \\
\hline $20-25$ & $22(45.8 \%)$ \\
\hline More than 25 & $8(16.7 \%)$ \\
\hline \multicolumn{2}{|l|}{ Mean \pm SD : $21 \pm 4$} \\
\hline \multicolumn{2}{|l|}{ Parity $(n=48)$} \\
\hline 0 & $1(2.1 \%)$ \\
\hline 1 & $8(16.66 \%)$ \\
\hline 2 & $4(8.33 \%)$ \\
\hline 3 & $20(41.66 \%)$ \\
\hline 4 & $8(16.66 \%)$ \\
\hline $\begin{array}{c}>_{,}=5 \\
(\text { Mean } \pm \text { SD: } 3.3 \pm 1.2) .\end{array}$ & $7(14.6 \%)$ \\
\hline \multicolumn{2}{|l|}{ Menopausal Status } \\
\hline Pre-menopausal & $23(47.9 \%)$ \\
\hline Post-menopausal & $25(52.1 \%)$ \\
\hline \multicolumn{2}{|l|}{ Duration of Reproductive Period } \\
\hline Less than 25 & $8(16.7 \%)$ \\
\hline $25-30$ & $9(18.8 \%)$ \\
\hline $31-35$ & $29(60.4 \%)$ \\
\hline
\end{tabular}




\begin{tabular}{|c|c|}
\hline More than 35 & $2(4.2 \%)$ \\
\hline Mean \pm SD : $31 \pm 4.3$ & \\
\hline OC Pills Use & $15(31.25 \%)$ \\
\hline Used & $33(68.75 \%)$ \\
\hline Not used & Table 2. Distribution of Study Subjects \\
According to Hormonal Risk Factors ( $\mathbf{n}=\mathbf{4 8 )}$
\end{tabular}

In our study 25 patients were having carcinoma in left breast $(52.1 \%)$, while 23 patients had it in right breast (47.9\%). The lump size was $>5 \mathrm{~cm}$ in $52.1 \%$ of cases, while $33.3 \%$ of patients had lump size $>2-</=5 \mathrm{~cm} ; 64.6 \%$ of the patients had the lump in the upper and outer quadrant; $12.5 \%$ of patients had centrally located lump; $77.1 \%$ of the cases did not have any fixity, while $22.9 \%$ cases had fixity to the skin or underlying structures like pectoralis muscle and chest wall. In this study 29 patients (60.4\%) had clinically palpable lymph nodes. $T$ staging of breast carcinoma revealed, T2 tumour was present in 16 females (33.3\%). T3 and T4 tumours were present in $14(29.2 \%)$ and 11 (22.9\%) cases respectively. Only 7 patients (14.6\%) were having T1. Nodal staging revealed N0 in 16 cases $(33.3 \%)$ and $\mathrm{N} 1$ and N2 stage was present in 15 (31.3\%) and 17 (35.4) cases respectively. Clinically, stage III disease was present in 22 patients (45.8\%), while stage II and I carcinoma breast was present in 19 (39.6\%) and 7 (14.6\%) patients.

In the present study about $64.6 \%$ showed infiltrating ductal carcinoma on FNAC, while $33.3 \%$ were suggestive of malignancy. Histopathological evaluation revealed that in 39 females $(81.3 \%)$ the breast carcinoma was of infiltrating duct carcinoma type, in 4 cases (8.3\%) it was of lobular type. While medullary type of breast carcinoma was detected histologically in 5 patients $(10.4 \%)$. Out of these 48 specimens of breast carcinoma breast 29 were ER positive (60.4\%), while 25 were PR positive (52.1\%). Her-2/neu status was positive in only 6 of the cases $(12.5 \%)$. In patients studied, all $48(100 \%)$ patients undergone surgery in the form of MRM. All patients of locally advanced breast carcinoma (22) were given neoadjuvant chemotherapy and advised postoperative radiotherapy. But postoperative radiotherapy was taken by 15 patients only; 39 patients $(81.3 \%)$ were advised postoperative chemotherapy. All 35 patients with hormone receptor positive (73.9\%) were advised hormonal therapy for 5 years. Postoperative complications include seroma and wound infection in 3 cases each (6.3\%). Flap necrosis and lymphoedema was noted in 1 patient each $(2.1 \%)$. No complications were noted in rest 40 patients (83.2\%).

\begin{tabular}{|c|c|}
\hline Characteristics & Subjects and \% \\
\hline Fine Needle Aspiration Cytology & $48(100 \%)$ \\
\hline Histological Subtype of Tumour & \\
\hline Infiltrating ductal carcinoma & $39(81.3 \%)$ \\
\hline Lobular carcinoma & $4(8.3 \%)$ \\
\hline Medullary carcinoma & $5(10.4 \%)$ \\
\hline & \\
\hline & \\
\hline Stage of Carcinoma Breast & $7(14.6 \%)$ \\
\hline I & $19(39.6 \%)$ \\
\hline II & $22(45.8 \%)$ \\
\hline III & \\
\hline Hormone Receptor Status &
\end{tabular}

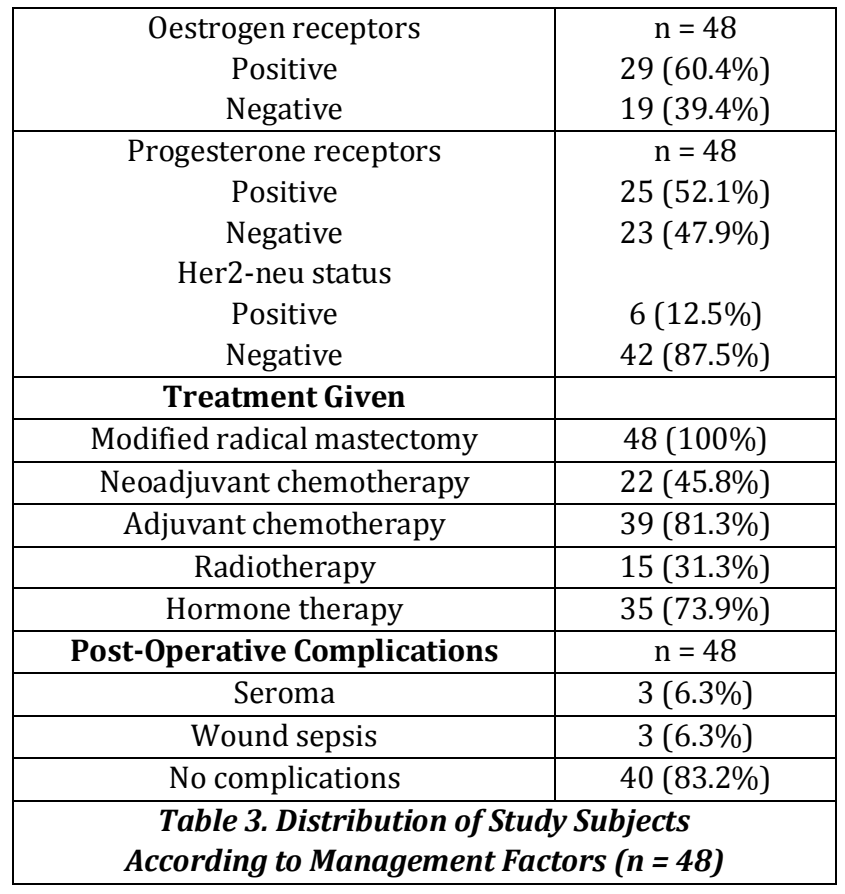

\section{DISCUSSION}

This hospital-based prospective observational study has been attempted to focus on the basic clinico-pathologic features of carcinoma breast with the various diagnostic and therapeutic modalities. Although, many advanced investigations are not performed at our centre, especially ER, PR, Her2-neu for which we sent sample to higher centre. Advanced malignancies were excluded from the study. Surgery was performed on all the cases in the study. Other treatment options advised according to the stage of disease. Breast carcinoma is mainly a disease of old age with peak incidence in fifth to sixth decade, but in India the disease was seen a decade earlier, probably because of shorter lifespan of Indian women. In present study, peak incidence of breast cancer was $43.7 \%$ between 41 - 50 years with second most incidences seen in 51 - 60 years' age group. In Balasubramaniam et al series, ${ }^{11}$ highest incidence was seen in 41 - 50 years' age group. Mean age was 51 years, which is in concordance to age of 47.39 years quoted by Sandhu et al.12 The youngest patient was of 29 years and oldest was 78 years.

Early age at menarche has been associated with an increased risk of breast cancer. China has an average age of menarche at 16 - 17 years of age, hence incidence of breast cancer is low. The results of study of Bhadoria AS et al ${ }^{13}$ revealed a strong association of reproductive factors with breast cancers in the Indian population. It is reported that women with menarche age of 10 or 11 years showed a 2.2 times higher risk for breast cancer compared to women who had their first menstrual period at 12 years and above. ${ }^{14}$ In our study, $50 \%$ of the patients had attained menarche between the age of 13 to 15 years and $35.4 \%$ less than 13 years of age, which is in concordance with Indian study done by Babita et al.15 Mean age of attainment of menarche is 13 years. Late menopause is a known risk factor of carcinoma of breast. The risk doubles with menopause after age 55.16 In this study, $52.1 \%$ of patients were postmenopausal and $47.9 \%$ patients were pre-menopausal, which is in concordance with study done by Raina V et al. ${ }^{17}$ Studies have shown that greater the duration of reproductive period, greater is the risk of breast cancer. In the present study, it was noted that $64.6 \%$ of the patients had a reproductive period of more than 30 years, thus 
suggesting higher incidence with larger duration of reproductive period. We noted mean reproductive period of 31 years. The study done by Ramon JM et al ${ }^{18}$ indicates that parity is an independent risk factor associated to breast cancer and that the women with a late age at first full-term pregnancy constitute a high-risk group.

The earlier the age of first birth, lower is the risk of breast cancer. In present study $35.4 \%$ of patients were aged less than 20 years at the time of birth of first child, while $45.8 \%$ patients delivered their first child between 20 and 25 years of age. In study done by Babita et al, ${ }^{15} 66.4 \%$ of cases had delivered their first child between the age of 20 - 25 years. Mean age at first birth was 21 years. Various studies have shown that breast fed women had given a protective effect against breast cancer. In our study, all 47 patients had breastfed their children for more than 6 months in duration. Hence, the protective nature of breast feeding for breast cancer could not be well correlated. One patient was nulliparous. Ewertz $\mathrm{M}$ et $\mathrm{al}^{19}$ suggested that full-term pregnancies protect against breast cancer. Women who never had any pregnancy were at increased risk and the risk decreased with an increasing number of full-term pregnancies. ${ }^{19}$

In this study, $58.3 \%$ of patients had parity $3-4,25 \%$ patient had parity $1-2$. Only one patient was nulliparous. Mean parity was 3.3 child births. So looking at the data, no relationship between parity and incidence of breast cancer could be drawn. A family history of breast cancer in first or second-degree relatives is associated with an increased risk of the disease. The risk is greatest in patients with first-degree relatives and age of presentation is years earlier than other patients. In the studies done by Pakseresht $\mathrm{S}$ et $\mathrm{al}^{20}$ and Zhu et al, ${ }^{21}$ both noted $3.4 \%$ of patients had a family history of disease. In another study done by Kelly et al, $40 \%$ of patients had a family history of carcinoma of breast. 22 In our study, $8.3 \%$ of patients had a family history of disease and most of them had early presentation. Patients in the Western population present at an early stage of disease due to awareness and good screening programmes. In India due to negligence and lack of widespread screening facilities, patients do present later during the course of the disease.

We noted $43.8 \%$ of our patients were presented more than 6 months of onset of symptoms, $33.3 \%$ of patients presented within 4 months - 6 months of onset of symptoms. Study done by Sandhu DS et al,12 37.5\% patients present within 3 months duration. Most breast cancers will present as a hard lump. There are various other presentations, which are less common. In our series, all 48 cases $(100 \%)$ presented with history of lump in the breast. In study done by Raina $\mathrm{V}$ et al, $96.5 \%$ of patients presented with a lump in breast. ${ }^{17}$ The second most common symptom in the series were nipple retraction which was seen in $33.3 \%$ of the patients, pain was present in $15.8 \%$. Nipple discharge and skin changes were present in $10.4 \%$ and $18.8 \%$ of patients respectively. Raina V et al ${ }^{17}$ reported $15.8 \%$ of patients presented with pain and $4.9 \%$ with nipple discharge. ${ }^{17}$ Cancer in both left and right breasts showed almost equal incidence. In our study, $47.9 \%$ of patients had a right-sided pathology and $52.1 \%$ had a leftsided pathology, which is comparable with the study done by Sandhu DS et al, ${ }^{12}$ Channanna et $\mathrm{al}^{23}$ and Park et al. ${ }^{24}$ Greater the size of the tumour, greater are the chances of the disease to be generalised and greater are the difficulties to treat. In our study $52.1 \%$ of patients had size of tumour more than $5 \mathrm{~cm}$,
$33.3 \%$ of patients had size 2 to $5 \mathrm{~cm}$ which is comparable to study done by Widodo I et al. .25 We noted $64.6 \%$ of lump were present in upper outer quadrant and $12.5 \%$ in central quadrant of breast. Mohapatra $\mathrm{M}$ et al reported $65 \%$ of tumours were present in upper outer quadrant.26 The occurrence of carcinoma more in Upper Outer Quadrant is explained by the fact that it has more of breast tissue than other areas. Only $22.9 \%$ of the cases had fixity to skin or the chest wall, while $77.1 \%$ had no fixity. Earlier studies have shown that $78 \%$ of the patients present with palpable axillary lymph nodes. But it was seen in our study that $60.4 \%$ of the patients had positive axillary lymph nodes and $39.6 \%$ did not have any palpable nodes.

In the present study $14.6 \%$ of patients had stage I disease, $39.6 \%$ had stage II disease and $45.8 \%$ had stage III disease. Channanna et al noted $12 \%$ of patients had stage I disease, $39 \%$ had stage II disease, $49 \%$ of patients had stage III disease. ${ }^{23} \mathrm{~T} 2$ was the most common stage in our study (33.3), next was T4 in $22.9 \%$ of cases. Patients in all N stages were almost similar in number (N1, N2, N3). There were no N4 patients in the study. Stage IV patients were not included in our study. In the present study about $64.6 \%$ cases showed infiltrating ductal carcinoma on FNAC, while $33.3 \%$ were suggestive of malignancy. One patient showed infiltrating lobular carcinoma. Postoperative histopathological evaluation revealed 39 cases $(81.3 \%)$ were of infiltrating ductal carcinoma (not otherwise specified) type, 4 cases (8.3\%) were of lobular carcinoma and 5 cases $(10.4 \%)$ were of medullary carcinoma. In study done by Vishal G et al, ${ }^{27} 88 \%$ of cases were of infiltrating ductal carcinoma. Various other studies showed similar distribution of patients according to histopathological subtypes. In present study, tissue samples of 29 patients (60.4\%) were ER positive, while 25 patient's tissue samples (52.1\%) were PR positive. Her-2/Neu status was positive in only 6 cases $(12.5 \%)$. Study done by Onitilo AA et al 28 and Patnayak $\mathrm{R}$ et $\mathrm{al}^{29}$ showed somewhat similar results. We included early (Stage I and II) and locally advanced (Stage III) breast cancers in this study. Mudholkar VG et al ${ }^{30}$ also reported, the upper outer quadrant was the most commonly affected quadrant in breast malignancy (42.5\%) and the invasive ductal carcinoma not otherwise specified was the most common (88\%) type.

Surgery was offered to all 48 patients in the form of Modified Radical Mastectomy (MRM). Axillary clearance was done in all cases to explore the axilla to look for nodal involvement even in clinically node negative cases. In most cases, lymph node dissection was done up to level II, but in some selected cases it was also done up to level III. If any infiltration to pectoralis major was found, the part of the muscle was excised. Pectoralis minor were either retracted or divided in most cases to gain access to level II and III lymph nodes. Thus surgery was aimed to provide adequate local clearance from tumour.

Neoadjuvant chemotherapy was given to all 22 patients with Locally Advanced Breast Carcinoma or Stage III disease. CAF regimen was advised to all patients with 2-3 cycles depending on the response to chemotherapy by the tumour. Remaining cycles were completed on adjuvant setting. Adjuvant chemotherapy was given to 39 patients with, 1) Tumour size more than or equal to $5 \mathrm{~cm}$; 2) Stage N1, N2 lymph node; 3) Her-2/neu receptor positive status; and 4) Triple negative breast carcinoma. CAF regimen was advised to all 
patients with total of 6 cycles (including cycles in neoadjuvant setting). If patient has IHD or other cardiac abnormalities then Adriamycin (Doxorubicin) was not given, as it has cardiac toxicity. Instead patient was advised Taxanes with platinum compounds (Docetaxel + Carboplatin/Paclitaxel + Cisplatin) according to a feasibility of the patient. Overall survival or Disease-Free Survival (DFS) is not influenced by the timing of chemotherapy (before or after surgery), but is more likely to be influenced by the chemo-sensitivity of the primary lesion. The only benefit that neoadjuvant systemic therapy offers is the feasibility of breast conservation, not at the cost of local recurrence as thought earlier. ${ }^{31}$

Radiotherapy was advised to all 22 patients with stage III disease. Radiotherapy was given to both operative area and ipsilateral axilla. For same we had referred the patient to the higher centre. All 35 receptor positive cases were advised hormonal therapy. Tamoxifen were advised to all patients irrespective of menopausal status for 5 years in a dose of 20 $\mathrm{mg} /$ day. All post-menopausal patients were advised with letrozole $2.5 \mathrm{mg}$ twice a day for 5 years. All 6 patients with Her$2 /$ neu positive were advised to take Trastuzumab, but none of them took the same because of cost of treatment.

All 22 patients with Locally Advanced Breast Carcinoma were advised Neoadjuvant Chemotherapy (NACT) in the form of CAF regimen or alternative as mentioned above every 21 days for 2 - 3 cycles depending on response to chemotherapy. Once size of tumour was reduced or fixity was decreased; patients were followed with Modified Radical Mastectomy (MRM) for local clearance followed by postoperative chemoradiation. All patients with hormone receptor positive were provided with hormonal therapy in the form of Tamoxifen or letrozole in doses mentioned above. Regular followup of patients done every three months in order to early identification of recurrence or metastasis. Followup done with chest $\mathrm{x}$-ray, USG abdomen pelvis, CT scan, Bone scan and whole body PET-CT scan if required. Till end of study means followup of 10 months was done. Two patients with recurrence was diagnosed.

In our study, $83.2 \%$ of cases were discharged without any complications; $6.3 \%$ of cases had seroma formation, $6.3 \%$ patients had sepsis at suturing site, $2.1 \%$ patient had flap necrosis, $2.1 \%$ patient had upper limb lymphoedema. In the study done by Sandhu DS et al,12 $25.3 \%$ of patients had lymphorrhea/seroma, flap necrosis was seen in $4.8 \%$ of patients and wound infection was seen in $2 \%$ of patients.

\section{CONCLUSION}

1. Highest incidence of carcinoma breast was found between fourth and fifth decade of life and early age of menarche has predisposition towards carcinoma breast.

2. Greater the duration of reproductive period, higher is the chance of breast cancer.

3. Increased risk is noted in patients with family history with earlier age of presentation in such patients.

4. Lump in breast was the most common presenting complaint and upper outer quadrant was the commonest site for breast cancer. Both right and left sides are equally affected.

5. Most cases presents with larger size of lump. Palpable axillary lymph nodes belonged to Stage II and Stage III, which reflected the negligence on part of patient and need to increase awareness among the population.
6. Infiltrating ductal carcinoma was the most common histopathological type.

7. A significant proportion of patients were hormone receptor positive depicting the role of hormonal therapy in the management.

8. For early breast carcinomas, Modified Radical Mastectomy with chemoradiation was treatment of choice. Locally Advanced Breast Carcinoma requires a complex multidisciplinary approach. Neoadjuvant chemotherapy followed by surgery followed by chemoradiation is recommended.

\section{REFERENCES}

1. Brunicardi FC, Anderson DK, Billiar T, et al. Schwartz's principles of surgery. $9^{\text {th }}$ edn. New York: Mc Graw Hill 2010;17:423-74.

2. Sainsbury R. The breast. In: Williams NS, Bulstrode CJK, O'Connell PR. Bailey \& Love's short practice of surgery. 25th edn. Hodder Arnold 2008:827-48.

3. Park K. Epidemiology of chronic non communicable diseases and condition, cancer. Chapter 6. Textbook of preventive and social medicine. 20th edn. Banarasidas Bhanot publisher 2009:p. 338.

4. www.medindia.net/news/view_news_main.asp? $x=7279$ a $\mathrm{s}$ accessed on 14.10.2010.

5. National cancer registry programme report (1981-2001) http://www.icmr.nic.in/ncrp/cancer regoverrview.htm.

6. Siddiqi M, Sen U, Mondal SS, et al. Cancer statistics from non-ICMR registries: population based registries. CRAB (Cancer registry Abstract) Newsletter of the National Cancer Registry Project of India 2001:47-59.

7. National Cancer Registry Programme, Indian Council Of Medical

Research http://www.icmr.nic.in/ncrp/ncrp_p/cancer_reg.pdf.

8. Nandkumar A, Gupta PC, Gangadharan P, et al. Geographic pathology revisited: development of an atlas of cancer in India. Int J Cancer 2005;116(5):740-54.

9. Agarwal G, Ramakant P. Breast cancer care in India: the current scenario and the challenges for the future. Breast Care (Basel) 2008;3(1):21-7.

10. Morris PJ, Wood WC. Oxford textbook of surgery. $2^{\text {nd }}$ edn. London: Oxford University Press 2000;21:1169-91.

11. Balasubramaniam SM, Rotti SB, Vivekanandam S. Risk factors of female breast carcinoma: a case control study at Puducherry. Indian J Cancer 2013;50(1):65-70.

12. Sandhu DS, Sandhu S, Karwasra RK, et al. Profile of breast cancer patients at a tertiary care hospital in north India. Indian J Cancer 2010;47(1):16-22.

13. Bhadoria AS, Kapil U, Sareen N, et al. Reproductive factors and breast cancer: a case-control study in tertiary care hospital of north India. Indian J Cancer 2013;50(4):31621.

14. Peeters PH, Verbeek AL, Krol A, et al. Age at menarche and breast cancer risk in nulliparous women. Breast Cancer Res Treat 1995;33(1):55-61.

15. Babita R, Kumar N, Karwasra RK, et al. Reproductive risk factors associated with breast carcinoma in a tertiary care hospital of north India: a case-control study. Indian J Cancer 2014;51(3):251-55.

16. Townsend CM, Beauchamp RD, Evers BM, et al. Sabiston textbook of surgery. the biological basis of modern surgical practice. 18th edn. Vol. 1. Philadelphia: Saunders 2008;7:851-916. 
17. Raina V, Bhutani M, Bedi R, et al. Clinical features and prognostic factors of early breast cancer at a major cancer center in north India. Indian J Cancer 2005;42(1):40-5.

18. Ramon JM, Escriba JM, Casas I, et al. Age at first full-term pregnancy, lactation and parity and risk of breast cancer: a case-control study in Spain. Eur J Epidemiol 1996;12(5):449-53.

19. Ewertz M, Duffy SW. Risk of breast cancer in relation to reproductive factors in Denmark. $\mathrm{Br} \mathrm{J}$ Cancer 1988;58(1):99-104.

20. Pakseresht $S$, Ingle GK, Bahadur AK, et al. Risk factors with breast cancer among women in Delhi. Indian J Cancer 2009;46(2):132-8.

21. Zhu MZ, Yu XF, He XM, et al. Clinicopathological features of invasive lobular carcinoma of the breast: a nationwide multicenter study in China. J Cancer Res Ther 2015;11 (Suppl 1):C89-94.

22. http://www.webmd.com/breastcancer/news/2008111 7/family history-raises-breast-cancer-risk

23. Channanna C, Narayana SK, Ramesh K. Clinical profile of patients with breast carcinoma attending tertiary care hospital. RRJMHS 2014;3(4):155-158.

24. Park JS, Choi DH, Huh SJ, et al. Comparison of clinicopathological features and treatment results between invasive lobular carcinoma and ductal carcinoma of the breast. J Breast Cancer 2015;18(3):28590.
25. Widodo I, Dwianingsih EK, Triningsih E, et al. Clinicopathological features of Indonesian breast cancers with different molecular subtypes. Asian Pac J Cancer Prev 2014;15(15):6109-13.

26. Mohapatra M, Satyanarayana S. Evaluation of clinico: pathologic findings of breast carcinoma in a general hospital in southern India. Indian $\mathrm{J}$ Cancer 2013;50(4):297-301.

27. Arya RC, Minj MK, Tiwari AK, et al. Prevalence of breast cancer in patients attending CIMS, Bilaspur, CG.: a tertiary hospital based study. Journal of Evidence based Medicine and Healthcare 2015;2(40):6773-8.

28. Onitilo AA, Engel JM, Greenlee RT, et al. Breast cancer subtypes based on ER/PR and Her2 expression: comparison of clinicopathologic features and survival. Clin Med Res 2009;7(1-2):4-13.

29. Patnayak R, Jena A, Rukmangadha N, et al. Hormone receptor status (estrogen receptor, progesterone receptor), human epidermal growth factor-2 and p53 in south Indian breast cancer patients: a tertiary care center experience. Indian J Med Paediatr Oncol 2015;36(2):11722.

30. Mudholkar VG, Kawade SB, Mashal SN. Histopathological study of neoplastic lesions of breast. Indian Medical Gazette 2012:353-363.

31. Raut NV, Chordiya N. NEO adjuvant chemotherapy in breast cancer: what have we learned so far? Indian J Med Paediatr Oncol 2010;31(1):8-17. 